\title{
Correlation between Serum Malondialdehyde and sVCAM-1 in Pediatric Thalassemic Patients with Hypercoagulation
}

\author{
Mira Haryanti Hartadi, Lelani Reniarti, Heda Melinda Nataprawira \\ Department of Child Health, Faculty of Medicine, Universitas Padjadjaran, Bandung, Indonesia \\ Email: mira.haryanti@ymail.com
}

How to cite this paper: Hartadi, M.H., Reniarti, L. and Nataprawira, H.M. (2017) Correlation between Serum Malondialdehyde and sVCAM-1 in Pediatric Thalassemic Patients with Hypercoagulation. Open Journal of Pediatrics, 7, 109-117.

https://doi.org/10.4236/ojped.2017.73014

Received: June 13, 2017

Accepted: July 31, 2017

Published: August 3, 2017

Copyright $\odot 2017$ by authors and Scientific Research Publishing Inc. This work is licensed under the Creative Commons Attribution International License (CC BY 4.0).

http://creativecommons.org/licenses/by/4.0/

\begin{abstract}
Introduction: Repeated blood transfusions with increased intestinal iron absorption in thalassemia causes iron overload, catalyzed production of various reactive oxygen species subsequently trigger oxidative stress. Endothelial as the first organ exposed to reactive oxygen species would suffer a marked increase in adhesion molecule due to endothelial dysfunction that will trigger a hypercoagulation. Objective: To investigate the correlation between oxidative stress status (malondialdehyde, MDA) and endothelial dysfunction (serum Vascular Cell Adhesion Molecule-1, sVCAM) in iron overload pediatric thalassemic patients with hypercoagulation. Methods: A cross-sectional study was conducted on thalassemic subjects with inclusion criteria: aged $5-14$ years with iron overload who had hypercoagulation based on TEG (Thromboelastography) examination. The determination of thalassemia degree was based on a Novel scoring system. The correlation between serum MDA and sVCAM-1 was analyzed using Rank Spearman, with a significance value of 5\% and $95 \%$ confidence intervals. Results: Nineteen male and twelve female children were included in the study. All subjects had pretransfusion $\mathrm{Hb}<9$ $\mathrm{g} / \mathrm{dL}$ and the nutritional status of moderate malnutrition. The results showed a moderately positive significant correlation between serum MDA and sVCAM-1 levels $(p=0.02, \mathrm{r}=0.416)$. The results also showed that there was a significant difference between serum MDA and thalassemia degree $(p=0.029$, $<0.05$ ), whereas levels of serum MDA in severe degree of thalassemic group were higher than in moderate degree group based on analysis using unpaired t-test $(p=0.026)$. Conclusions: Serum MDA level as stress oxidative status marker has moderately positive correlation with sVCAM-1 as endothelial dysfunction marker in iron overloaded pediatric thalassemic patients with hypercoagulation.
\end{abstract}




\section{Keywords}

Pediatric, Thalassemia, Malondialdehyde, sVCAM-1, Hypercoagulation

\section{Introduction}

Thalassemia is one of the common forms of hereditary disorders due to abnormalities in single genes caused by about 200 mutations in the gene encoding the globin chains. On beta-thalassemia, beta globin chain synthesis absent or reduced, causing the production of excess alpha chains. Excess alpha chains will cause the erythrocytes to become more fragile, easily crushed, thus resulting in ineffective erythropoiesis and various degree of anemia [1]. Patients with thalassemia major will require repeated blood transfusions to survive due to severe anemia [2]. Repeated blood transfusions in major beta-thalassemia and the increase of iron intestinal absorption will cause excess iron accumulation in various tissues of the body. As a consequence of the presence of secondary excess iron there was production of various reactive oxygen species (ROS). An increase of ROS in the erythrocyte will cause oxidative stress [3] [4]. Oxidative stress causes lipid peroxidation, characterized by increased levels of malondialdehyde (MDA), a well-recognised biomarker of lipid peroxidation. Lipids are a group of biomolecules that are most involved in the process of oxidative stress. Chronic intravascular hemolysis which occurs in thalassemia is also associated with increased prooxidant factors and proinflammatory endothelial dysfunction, as the first organ exposed by the ROS, one of which is characterized by subsequent coagulopathy that will cause vasomotor dysregulation and vasculopathy. Endothelial dysfunction characterized by increase in adhesion molecules such as sVCAM-1, the only adhesion molecules which expressed by endothelial cells only when there is inflammation or infection stimulus [5] [6].

Endothelial dysfunction is an early marker to detect cardiovascular disease characterized by a decrease in endothelial vasodilatation and also an increase in proinflammatory status and prothrombotic components [5] [7] [8]. The hemolysis process which occurs in thalassemia is also directly related to endothelial damage. Recent data indicated that chronic intravascular hemolysis had a role in the occurrence of endothelial dysfunction [5] [6]. Endothelial dysfunction can lead to a hypercoagulable state which can be characterized by the occurrence of thromboembolic events. A study of thalassemic patients carried out in the Dr. Hasan Sadikin Hospital found 70\% of children who experienced a hypercoagulable state had no obvious symptoms and might also occur before clinical manifestations arise [9]. This raised awareness of the presence of chronic hypercoagulable state in pediatric patients with thalassemia. Therefore, we decided to analyze the correlation between serum MDA which represented oxidative stress status and serum SVCAM-1 which represented endothelial dysfunction in iron overload (serum ferritin levels $>1.000 \mu \mathrm{g} / \mathrm{L}$ ) [3] pediatric thalassemic patients. 


\section{Materials and Methods}

Subjects were iron overload thalassemic patients, had hypercoagulable state, and aged 5 - 14 years who visited the pediatric Hemato-oncology division of Dr. Hasan Sadikin General Hospital, a tertiary level university teaching hospital in West Java, Indonesia, to get regular red blood cell transfusion and iron chelating agent. The exclusion criteria were patients with chronic disease such as cardiovascular disease, infections and had a nutritional status of severe malnutrition. This was a cross-sectional analytic study. Sample collection was conducted on March 2015. This study was approved by the ethical committee of the Faculty of Medicine, Universitas Padjadjaran/Dr. Hasan Sadikin General Hospital Bandung, Indonesia.

All subjects who met the inclusion criteria performed TEG examination. Furthermore subject with a hypercoagulable based on TEG results will be checked for serum MDA and sVCAM-1, after informed consent were obtained from the patient's subjects. Malondialdehyde (MDA) is a lipid peroxidation products which was examined in the laboratory of Dr. Hasan Sadikin General Hospital using Enzyme linked Immunoassay (ELISA) technique (Unit: ng/mL) [10]. Soluble vascular cell adhesion molecule-1 sVCAM-1 is a cell adhesion molecule which is expressed by endothelial cells stimulated by inflammation or infection, are also examined by the ELISA technique (Unit: $\mathrm{ng} / \mathrm{mL}$ ) [11] [12]. The determination of thalassemia degree is based on a Novel scoring system which classified thalassemia into mild, moderate, and severe group [13]. Hypercoagulable status, an inherited or acquired condition that can cause pathological thrombotic tendencies resulting from blood abnormalities or changes in blood vessels, was assessed by examining thromboelastography (TEG), which assess hemostatic function, platelets, and fibrinolysis globally, comprehensively, and simultaneously [14] [15].

The correlation between MDA and SVCAM-1 levels were analyzed statistically using Pearson or the rank Spearman correlation test if the data were not normally distributed. The significance of test results is determined based on the value of $p<0.05$. Variables of this study were numerical and categorical, so the test used to compare the 2 groups was unpaired t-test or Mann-Whitney if it was not eligible for parametric test. Whereas the test used to compare more than two groups was one-way ANOVA or Kruskal-Wallis otherwise eligible parametric test. In this study, data normality test used is the Shapiro-Wilk because the sample size is $\leq 50$.

\section{Results}

During March 2015 there were 97 subjects aged 5 - 14 years and we found 31 subjects (determined by power calculation for correlation test) who met inclusion criteria. The majority of the research subjects were 10 years and older (61.29\%) and were mostly male. Based on a length of illness and the degree of thalassemia, the majority of subjects suffered from thalassemia for $>10$ years 
with moderate degree. All subjects had pretransfusion $\mathrm{Hb}$ level $<9 \mathrm{~g} / \mathrm{dL}$ and the nutritional status were moderately malnourished. In the majority of subjects (74.19\%) received deferiprone as iron chelating agent with treatment adherence was not significantly different between the optimal and not optimal group, and only two subjects had undergone splenectomy.

There was significant differences when comparing the MDA levels with the degree of thalassemia, where moderate degree of thalassemia group had lower levels of serum MDA than severe degree, with $p$-value $=0.026$ (Table 1 ). Table 2 shows no significant differences found between sVCAM-1 levels and subjects' characteristics.

Table 1. Comparison of MDA levels with gender, age, length of illness, type of thalassemia, thalassemia degrees, iron chelating agent, and treatment adherence.

\begin{tabular}{|c|c|c|c|c|c|}
\hline \multirow{2}{*}{ Variables } & \multicolumn{4}{|c|}{ MDA level (ng/mL) } & \multirow{2}{*}{$p$-value } \\
\hline & $\mathrm{N}$ & Mean (SD) & Median & Range & \\
\hline Sex & & & & & $0.997^{\dagger}$ \\
\hline Male & 19 & $82.6(18.2)$ & 85.8 & $47-112$ & \\
\hline Female & 12 & 81.5 (17.7) & 84.9 & $52.5-105.1$ & \\
\hline Age & & & & & $0.527^{\dagger}$ \\
\hline$<10$ years & 12 & $79(17.1)$ & 81.6 & $47-98.7$ & \\
\hline$\geq 10$ years & 19 & $82.3(18.4)$ & 86.2 & $52.5-112$ & \\
\hline Length of illness & & & & & $0.898^{*}$ \\
\hline$<5$ years & 6 & $78.8(22.2)$ & 88.1 & $47-97.5$ & \\
\hline $5-10$ years & 10 & $81.2(14.6)$ & 86.2 & $54-98.7$ & \\
\hline$>10$ years & 15 & $82,9(18,8)$ & 84.7 & $52.5-112$ & \\
\hline Type of Thalassemia & & & & & $0.066^{\dagger}$ \\
\hline Major & 16 & $87.2(16.8)$ & 87.3 & $52.2-112$ & \\
\hline Intermedia & 15 & $75.5(17.2)$ & 75.2 & $47-98.7$ & \\
\hline Thalassemia degrees & & & & & $0.026^{\dagger}$ \\
\hline Moderate & 20 & $76.4(17.3)$ & 77.7 & $47-105.2$ & \\
\hline Severe & 21 & $91(15)$ & 95.5 & $65.7-112$ & \\
\hline Iron chelating agent & & & & & $0.902^{\dagger}$ \\
\hline Deferiprone & 23 & $81.8(18.8)$ & 85.8 & $47-112$ & \\
\hline Deferasirox & 8 & $80.9(15.4)$ & 85.4 & $54-100.4$ & \\
\hline Treatment adherence & & & & & $0.188^{\dagger}$ \\
\hline Optimal & 15 & $77.2(19.1)$ & 80.1 & $47-105.1$ & \\
\hline Not optimal & 16 & 85.7 (15.9) & 86.4 & $56.7-112$ & \\
\hline
\end{tabular}

${ }^{\dagger}$ unpaired t-test, ${ }^{\star}$ one-way ANOVA test, SD: standard deviation. 
Table 2. Comparisons of sVCAM-1 levels with gender, age, length of illness, type of thalassemia, thalassemia degrees, iron chelating agent, and treatment adherence.

\begin{tabular}{|c|c|c|c|c|c|}
\hline \multirow{2}{*}{ Variables } & \multicolumn{4}{|c|}{ sVCAM-1 levels (ng/mL) } & \multirow{2}{*}{$p$-value } \\
\hline & $\mathrm{N}$ & Mean (SD) & Median & Range & \\
\hline Sex & & & & & $0.570^{*}$ \\
\hline Male & 19 & $130.5(43.9)$ & 121.1 & $79.2-224.6$ & \\
\hline Female & 12 & $133.6(33.6)$ & 134.3 & $81.1-192.8$ & \\
\hline Age & & & & & $0.667^{\star}$ \\
\hline$<10$ years & 12 & $127.7(35.6)$ & 122.1 & $79.2-207.3$ & \\
\hline$\geq 10$ years & 19 & $134.2(42.8)$ & 123.2 & $81.1-224.6$ & \\
\hline Length illness & & & & & $0.875^{\dagger}$ \\
\hline$<5$ years & 6 & $135.7(44.1)$ & 131 & $79.2-207.3$ & \\
\hline $5-10$ years & 10 & $129.6(31.5)$ & 122.1 & $90.8-186.4$ & \\
\hline$>10$ years & 15 & $131.5(45)$ & 110.2 & $81.1-224.6$ & \\
\hline Type of thalassemia & & & & & $0.066^{*}$ \\
\hline Major & 16 & $141.2(16.8)$ & 126.8 & $84.2-224.6$ & \\
\hline Intermedia & 15 & $121.6(36.8)$ & 110.2 & $79.2-207.3$ & \\
\hline Thalassemia degrees & & & & & $0.386^{*}$ \\
\hline Moderate & 20 & $129.4(42.9)$ & 113.3 & $79.2-224.6$ & \\
\hline Severe & 21 & $135.8(34.6)$ & 128.2 & $84.2-212$ & \\
\hline Iron chelating agent & & & & & $0.240^{*}$ \\
\hline Deferiprone & 23 & $126.1(36.7)$ & 116.4 & $79.2-212$ & \\
\hline Deferasirox & 8 & $147.9(45.9)$ & 147.3 & $84.2-224.6$ & \\
\hline Treatment adherence & & & & & $0.217^{\star}$ \\
\hline Optimal & 15 & $122.5(33.7)$ & 123.2 & $79.2-105.1$ & \\
\hline Not optimal & 16 & $140.3(43.8)$ & 122.1 & $56.7-112$ & \\
\hline
\end{tabular}

${ }^{*}$ Mann-Whitney test, ${ }^{\dagger}$ Kruskal-Wallis test, SD: standard deviation.

Statistical test results using Spearman rank correlation analysis on the significance level of $5 \%$ showed a significant relationship between MDA with sVCAM-1 serum from pediatric thalassemic patients with hypercoagulation with $p=0.02$ and moderately positive correlation with $\mathrm{r}=0.416$.

\section{Discussion}

Based on the general characteristics of the subjects, we had 31 children consisted of 19 males and 12 females. The majority of the subjects (19/31) were over 10 years age with the youngest age was 6 years old. Rosendaal [16] stated that age increases the risk of thrombosis also in other study that had already stated that thrombosis may occur at the early age [17]. On the other hand, Tejasari et al. [9] mentioned that age was not a factor that is associated with a hypercoagulable 
state. Repeated blood transfusions especially in major beta-thalassemia with increasing the intestinal absorption of iron will cause excess iron accumulation in various tissues of the body. This is thought to be the underlying reason increased incidence of thrombosis in accordance with increasing of age.

Our study showed that the MDA levels, as a product of membrane lipid peroxidation due to oxidative stress, in all subjects remains high even though it has got deferiprone and desferasirox as iron chelating agents, optimal or not. This could cause by iron overload condition in subjects that causing oxidative stress. Another study stated that even in thalassemia major patients who received desferoxamine as iron chelating agent, iron overload in the body remains high [18].

Based on statistical test using Rank Spearman, our study showed a moderately positive significant correlation between serum MDA with sVCAM-1 levels ( $p=$ $0.02, r=0.416)$. The statistical test used in this study was Rank Spearman due to sVCAM-1 distribution is not normal. Form and strength of the correlation between serum MDA with sVCAM-1 in this study explained that in conditions of oxidative stress that causes endothelial dysfunction attachment of erythrocytes and leukocytes to vascular endothelium suggested there was instability that could lead to a hypercoagulable state. Another study also stated that endothelial injury or activation aiding in the recruitment of white blood cells and erythrocytes, promoting thrombosis [12]. Increased levels of endothelial adhesion proteins characterized by increased levels of sVCAM-1 occurs when the production of reactive oxygen species increased due to iron overload. Our study subjects who did not receive supplementation of antioxidants (vitamin E) due to the unavailability of antioxidants supplement from the Government health insurance. On the other hand it shows that the levels of serum MDA and sVCAM-1 on our subjects was not influenced by the administration of antioxidants.

In our study, a comparison between serum sVCAM-1 levels and gender, age, length of disease, thalassemia type, degree of thalassemia, type of iron chelating agent as well as treatment adherence showed no significant difference (Table 2). On the other hand, a comparison between serum MDA levels and subjects' characteristics only thalassemia degrees, based on unpaired t-test showed significant differences, where severe degree thalassemia group (score 7.5 - 10) had serum MDA levels higher than moderate degree thalassemia (score 4 - 7) (Table 1). The determination of the degree of thalassemia was based on a Novel scoring system that divides thalassemia degrees by 6 parameters: age at diagnosis (in years), age when received a first transfusion (in years), the frequency of transfusion requirements, spleen size $(\mathrm{cm})$, and the presence or absence of growth disorders, with a score range of 0 - 10. This scoring system basically classifies the severity of thalassemia intermedia which aim to improve the quality of management [13]. The application of this scoring system is more recommended in patients aged less than 10 years so the more effective management can be achieved, such as when to start giving transfusions and iron chelating agent, which could prevent increased clinical severity of intermediate thalassemia. Serum MDA levels were higher in subjects with severe degree thalassemia indicates 
that the lower the pretransfusion $\mathrm{Hb}$ level and more frequent transfusions, the higher the level of oxidative stress marker. It also shows the need for monitoring of signs leading to the occurrence of TEE, especially in patients with moderate and severe degree thalassemia.

Serum MDA levels in our study had a mean of $81.56 \mathrm{ng} / \mathrm{mL}$, median 85.8 $\mathrm{ng} / \mathrm{mL}$ and the range of $47-112 \mathrm{ng} / \mathrm{mL}$. In our study, assessment on healthy children was not conduct so the value of MDA in healthy subjects was not known. At present reference value for normal serum MDA levels has not existed. Increased levels of serum MDA on the thalassemia subjects compared to healthy subjects were caused by the absence of beta globin chains in beta-thalassemia patients lead to the accumulation of excess alpha globin chains, the presence of excess alpha globin chain was a primary cause of cellular oxidative damage as well as iron overload. As a result of increased levels of plasma iron and nonhemoglobin intracellular iron in thalassemia, production of ROS will be increased [19]. Furthermore, repeated blood transfusions will lead to iron overload thus increasing the production of free radicals and peroxidation damage on the tissue. As compensation for these conditions, this would decrease the levels of endogenous antioxidants, but in this study we did not measure antioxidants levels. Lipid peroxidation was indicated by elevated levels of serum MDA. Metabolic changes of iron and increased production of free radicals in thalassemia would offset the increased consumption of endogenous antioxidants indicating the need for administration of antioxidants such as vitamin E, which may give significant results in the fight against oxidative damage.

Serum sVCAM-1 levels in this study had a mean of $131.69 \mathrm{ng} / \mathrm{mL}$, median $123.1 \mathrm{ng} / \mathrm{mL}$ and ranges from 79.2 to $224.6 \mathrm{ng} / \mathrm{mL}$. Vascular adhesion molecules-1 is one of the adhesion molecules expressed by endothelial cells when endothelial dysfunction. The study by El-Kinawy and Andrawes [20] showed elevated levels of sVCAM-1 in patients with thalassemia compared to healthy control subjects. In this study, there was no assessment of sVCAM-1 serum levels in healthy subjects, but there were differences in the levels of sVCAM-1 by age, type of thalassemia, the degree of thalassemia, iron chelating agent types, as well as its treatment adherence where SVCAM-1 serum levels were higher in the group aged 10 years and over, thalassemia major, severe degree of thalassemia, use of deferasirox as iron chelating agent and on the subject of non-compliance, although not statistically significant. Increased levels of sVCAM-1 indicates the endothelial activation is higher, so the risk of thromboembolic manifestations as long-term complications become higher.

This study has several limitations including no assessment of serum MDA and sVCAM-1 levels in healthy subjects, so the normal values of serum MDA and sVCAM-1 in healthy subjects with similar demographic characteristics with our study subjects is not known, the symptoms that lead to the incidence of TEE were not accompanied by evidence of more objective investigations (eg. angiography, CT-scan, MRI), also the very few number of patients studied and the short study period. However, due to our limitations, more studies are needed. 


\section{Conclusion}

In conclusions, serum MDA level has moderately positive correlation with sVCAM-1 in iron overloaded pediatric thalassemic patients with hypercoagulation. So, iron overload increases the risk of thromboembolic events in children with hypercoagulation. We also found that there was a significant difference between serum MDA and thalassemia degree.

\section{Acknowledgements}

Our study was done with private funding. We thanked Professor Abdurachman Sukadi and Professor Herry Garna for initial manuscript preparation counseling. MHH and LR contributed to conception of the study. MHH, LR and HMN contributed to design of the study, acquisition of data, interpretation and analysis of data, revising the article and final approval of the version submitted. We also thank the children and adolescents for their participation in the present study.

\section{References}

[1] Mahdi, E.A. (2014) Relationship between Oxidative Stress and Antioxidant Status in Beta-Thalassemia Major Patients. Acta Chimica and Pharmaceutica Indica, 4, 137 145.

[2] Elizabeth, G. and Ann, T.J.A.M. (2010) Genotype-Phenotype Diversity of BetaThalassemia in Malaysia: Treatment Options and Emerging Therapies. Medical Journal of Malaysia, 65, 256-260.

[3] Hershko, C. (2007) Iron Loading and Its Clinical Implications. American Journal of Hematology, 82, 1147-1148. https://doi.org/10.1002/ajh.21070

[4] Emerit, J., Beaumont, C. and Trivin, F. (2001) Iron Metabolism, Free Radicals, and Oxidative Injury. Biomedical and Pharmacology Journal, 55, 333-339. https://doi.org/10.1016/S0753-3322(01)00068-3

[5] Balla, J., Vercellotti, G.M. and Jeney, V. (2005) Heme, Heme Oxygenase and Ferritin in Vascular Endothelial Cell Injury. Molecular Nutrition \& Food Research, 49, 1030-1043. https://doi.org/10.1002/mnfr.200500076

[6] Jeney, V., Balla, J. and Yachie, A. (2002) Pro-Oxidant and Cytotoxic Effects of Circulating Heme. Blood, 100, 879-887. https://doi.org/10.1182/blood.V100.3.879

[7] Akinsheye, I. and Klings, E.S. (2010) Sickle Cell Anemia and Vascular Dysfunction: The Nitric Oxide Connection. Journal of Cellular Physiology, 224, 620-625. https://doi.org/10.1002/jcp.22195

[8] Hahalis, G., Kremastinos, D.T. and Terzis, G. (2008) Global Vasomotor Dysfunction and Accelerated Vascular Aging in Beta-Thalassemia Major. Atherosclerosis, 198, 448-457. https://doi.org/10.1016/j.atherosclerosis.2007.09.030

[9] Tejasari, R.K., Reniarti, L. and Effendi, S.H. (2014) Faktor Risiko Hiperkoagulasi pada Penderita Thalassemia Anak. Ph.D. Thesis, Universitas Padjadjaran, Bandung.

[10] Kotani, K., Maekawa, M., Kanno, T., Kondo, A., Toda, N. and Manabe, M. (1994) Distribution of Immunoreactive Malondialdehyde-Modified Low-Density Lipoprotein in Human Serum. Biochimica et Biophysica Acta, 1215, 121-125. https://doi.org/10.1016/0005-2760(94)90100-7 
[11] Mcever, R. (2001) Adhesive Interactions of Leukocytes, Platelets, and the Vessel Wall during Hemostasis and Inflammation. Journal of Thrombosis and Haemostasis, 86, 746-756.

[12] Butthep, P., Bunyaratvej, A. and Funahara, Y. (1997) Possible Evidence of Endothelial Cell Activation and Disturbance in Thalassemia: An in Vitro Study. The Southeast Asian Journal of Tropical Medicine and Public Health, 28, 141-148.

[13] Sripichai, O., Makarasara, W., Munkongdee, T., Kumkhaek, C., Nuchprayoon, I. and Chuansumrit, A. (2008) A Scoring System for the Classification of Beta-Thalassemia/Hb E Disease Severity. American Journal of Hematology, 83, 482-484. https://doi.org/10.1002/ajh.21130

[14] Cappelini, M.D., Poggiali, E.T.A. and Musallam, K.M. (2012) Hypercoagulability in Beta-Thalassemia: A Status Quo. Expert Review of Hematology, 5, 505-512. https://doi.org/10.1586/ehm.12.42

[15] Alfirevic, Z. and Alfirevic, I. (2010) Hypercoagulable State, Pathophysiology, Classification and Epidemiology. Clinical Chemistry and Laboratory Medicine, 48, S15S26. https://doi.org/10.1515/CCLM.2010.371

[16] Rosendaal, R.F. (2005) Venous Thrombosis: The Role of Genes, Environment, and Behavior. American Society of Hematology Education Program, 1, 1-12.

https://doi.org/10.1182/asheducation-2005.1.1

[17] Eldor, A., Durst, R. and Hy-Am, E. (1999) A Chronic Hypercoagulable State in Patients with Beta-Thalassemia Major Is Already Present in Childhood. British Journal of Haematology, 107, 739-746. https://doi.org/10.1046/j.1365-2141.1999.01758.x

[18] Borgna-Pignatti, C., Rugolotto, S. and Stefano, P.D. (2004) Survival and Complications in Patients with Thalassemia Major Treated with Transfusion and Deferoxamine. Haematologica, 89, 1187-1193.

[19] Şimşek, F., Öztürk, G., Kemahlı, S., Erbaş, D. and Hasanoğlu, A. (2005) Oxidant and Antioxidant Status in Beta-Thalassemia Major Patients. Ankara Üniversitesi Tip Fakültesi, 58, 34-38.

[20] El-Kinawy, N.S. and Andrawes, N.G. (2012) Endothelial and Peripheral Blood Cell Activation in $\beta$-Thalassemia Children. Egyptian Journal of Haematology, 37, 156161.

Submit or recommend next manuscript to SCIRP and we will provide best service for you:

Accepting pre-submission inquiries through Email, Facebook, LinkedIn, Twitter, etc. A wide selection of journals (inclusive of 9 subjects, more than 200 journals)

Providing 24-hour high-quality service

User-friendly online submission system

Fair and swift peer-review system

Efficient typesetting and proofreading procedure

Display of the result of downloads and visits, as well as the number of cited articles

Maximum dissemination of your research work

Submit your manuscript at: http://papersubmission.scirp.org/

Or contact ojped@scirp.org 